\title{
EFEECT OF HEALTH EDUCATION PROGRAMME ON THE KNOWLEDGE REGARDING HAND WASHING AND IMMUNIZATION IN THE DISADVANTAGED COMMUNITY OF EASTERN NEPAL
}

\author{
Rajiv Karn, Bijay Thapa, Buna Bhandari, Archana Shrestha and Bashav Raj Dha adi
}

\begin{abstract}
Hand washing with soap can reduce the risk of diarrhoeal diseases. Hygiene behavior and sanitation is linked to our day-to-day life which includes hand washing practice. It is one of the basic elements of health. The objective of the study was to assess the knowledge level of the disadvantaged community regarding hand washing and immunization and compare the results of pre and post health education programme.

An intervention program was designed after the situation analysis from log book of Bachelor in Medicine and Bachelor in Surgery (MBBS) students. A face to face interview by trained medical students was conducted before and after intervention programme with the help of pre tested schedules. Thirty six individuals were interviewed of which $81 \%$ of the respondents had correct knowledge regarding hand washing prior to the intervention which was increased to $94 \%$ after intervention program. Thirty three percent of the people showed correct way of hand washing before demonstration which improved to $78 \%$ after intervention, a statistically significant observation. Knowledge about the consequences of poor sanitation did increase from $58 \%$ to $78 \%$.

With respect to immunization knowledge $86 \%$ of the respondents had heard about the immunization before the intervention and which increased to $92 \%$ after the intervention program. Nineteen percent correctly responded about the importance of immunization before the intervention and $28 \%$ after the intervention, which was statistically non significant improvement ( $\mathrm{P}$ value $>0.05$ ). Knowledge regarding Period of completion of immunization had increased from $77.8 \%$ to $91.6 \%$ which was highly significant ( $\mathrm{P}$ value $=0.001)$.

Knowledge level regarding adverse effect of not immunizing children increased by $9 \%$ with intervention. The intervention program had helped in increasing the knowledge level of the community regarding hand washing techniques and knowledge regarding immunization. Hence, we would recommend; continue to use demonstration technique to improve hand washing knowledge \& practice and wide approach intensive awareness program to enhance knowledge about immunization.
\end{abstract}

Key words: Hand washing knowledge, Immunization, Disadvantaged Community, Nepal

\section{Introduction}

Hand washing is very important for preventing infectious diseases as $80 \%$ of all infectious diseases are transmitted by touch. ${ }^{1}$
Washing hands with soap can reduce the risk of diarrhoeal diseases by $42-47 \%$ and interventions to promote "Hand washing" 
might save a million lives. ${ }^{2}$ Hand washing can significantly reduce many diseases which are the "major killers of the developing world. ${ }^{3}$

Hand washing can also prevent skin infections, eye infections, intestinal worms, SARS, and Avian Flu, and benefits the health of people living with people wash their hands with water only, and only $12 \%$ use soap. ${ }^{5}$ Hand washing with soap is a life saving intervention within the technological, financial, reach for all countries and communities. ${ }^{6}$ With regard to hand washing, there is a wide gap between knowledge $98 \%$ $\&$ practice $30 \%$ also there is a big gap of sanitation coverage between poor $12 \%$ and rich $80 \%{ }^{7}$ Such difference is hindering factor to change the people's behavior and thus one of the factor of poverty in developing countries.

The national immunization program (NIP) is one of the most prioritized programs of Government of Nepal, since 1979 which has reduced the burden of VPDs. The immunization coverage is more than $90 \%$ for all antigens under NIP. In Morang district, Bacillus Calmette-Guerin (BCG), Diptherial Pertusis and Tetanus (DPT-III), measles, and Japanese Encephalitis (JE) coverage are 93\%, $86 \%, 81 \%$ and $57 \%$ respectively ${ }^{8}$ for the year 2010-11. The coverage of immunization depends on knowledge level of community with regard to benefits and availability of immunization services.

Available data also shows the differences regarding coverage of immunization. Hence, this study was planned to assess the knowledge level of the disadvantaged community regarding hand washing and immunization and compare the results of pre and post intervention program.

\section{Materials and methods}

As a part of academics activities, "Family Health Exercise" programme from the Department of Community Medicine of Nobel Medical College Teaching Hospital and Research Center, the baseline data from Katahari VDC of ward number 1and 5 of Morang district was collected by the MBBS students for six month (Feb to July 2012). Ethical approval for the study was taken from the ethical committee of Nobel Medical College. The disadvantaged families were identified by convenient sampling method with the help of local Female Community Health Volunteer (FCHV). The disadvantaged community were people having no land, belongs to mushar communities. Orientation was given to the students about the study and then "One day intervention program" was organized for the identified community after obtaining verbal consent. Total 36 community people were participated in the program. Necessary information was obtained through face to face interview by MBBS students trained for the study with the help of pretested schedules before and after the intervention.

The intervention program was done through health exhibition, demonstration, health education lectures and dramas for four hours. The data were entered in excel sheet and descriptive analysis was done with SPSS-16. Non parametric test for two related sample McNemar test and Wilcoxon Signed Rank test were applied to find out statistical significance at the level of $\mathrm{P}<0.05$ between the pre and post intervention results. 


\section{Results}

Thirty six subjects had participated in the study. Table 1 shows, two third of the participant were from ward number 5. Most $(64 \%)$ of the respondents were female and among the respondents $89 \%$ were married. Fifty three percent were house wife and 33\% were laborer, $8 \%$ government job holders and $6 \%$ were agriculture by occupation. Seventy five percent of the respondents were not literate. The age of subjects ranged from 18-65 year with the mean age of 33.3 years and majority (64\%) were bellow 35 years of age.

Table 2 depicts $81 \%$ of the respondents had correct knowledge regarding hand washing during pre test which improved to $94 \%$ after intervention program, a statistically non Significant (P value $>0.05)$ increase. Regarding the correct way of demonstrating hand washing process knowledge level increased more than double (33\% to $78 \%)$, which was statistically significant $(\mathrm{P}$ value $<0.05$ ). However, improvement (from $58 \%$ to $78 \%$ ) with regard to knowledge about consequences of poor sanitation was

Table 1: Demographic Characteristics of Respondents

\begin{tabular}{|l|c|c|}
\hline Characteristics & $\begin{array}{c}\text { Frequenc } \\
\mathbf{y}(\mathbf{n = 3 6})\end{array}$ & Percent(\%) \\
\hline Ward Number & & \\
\hline 1 & 12 & 33.3 \\
\hline 5 & 24 & 66.7 \\
\hline Gender & & \\
\hline Male & 13 & 36.1 \\
\hline Female & 23 & 63.9 \\
\hline Age & & \\
\hline$<35$ years & 23 & 63.9 \\
\hline$>35$ years & 13 & 36.1 \\
\hline Marital Status & & \\
\hline Married & 32 & 88.9 \\
\hline Unmarried & 2 & 5.6 \\
\hline Widows & 2 & 5.6 \\
\hline Occupation & & \\
\hline Laborer & 12 & 33.3 \\
\hline Agriculture & 2 & 5.6 \\
\hline Government & 3 & 8.3 \\
\hline House wife & 19 & 52.8 \\
\hline Education & & \\
\hline Not literate & 27 & 75 \\
\hline Literate & 9 & 25 \\
\hline
\end{tabular}

Statistically non-significant.

Table 2: Knowledge regarding hand Washing and sanitation

\begin{tabular}{|l|c|c|c|}
\hline \multicolumn{1}{|c|}{ Characteristics } & $\begin{array}{c}\text { Pre Test } \\
\text { Frequency } \\
(\%)\end{array}$ & $\begin{array}{c}\text { Post Test } \\
\text { Frequency (\%) }\end{array}$ & $\begin{array}{c}\text { P value (McNemar } \\
\text { test) }\end{array}$ \\
\hline Knowledge on Process of Hand washing & & & \\
\hline Yes & $29(80.6)$ & $34(94.4)$ & \multirow{2}{*}{0.06} \\
\hline No & $7(19.4)$ & $2(5.6)$ & \\
\hline Demonstration of Hand washing & $12(33.3)$ & $28(77.8)$ & \multirow{2}{*}{0.001} \\
\hline Yes & $24(66.7)$ & $8(22.2)$ & \\
\hline No & & & \multirow{2}{*}{0.06} \\
\hline $\begin{array}{l}\text { Knowledge of diseases due to Poor } \\
\text { Sanitation }\end{array}$ & $21(58.3)$ & $28(77.8)$ & \\
\hline Yes & $15(41.7)$ & $8(22.2)$ & \\
\hline No & & & \\
\hline
\end{tabular}


Table 3 shows $86 \%$ of the respondents had heard and had knowledge about the immunization before the intervention and which increased to $92 \%$ after the intervention program. Nineteen percent correctly responded about the importance of immunization before the intervention and $28 \%$ after the intervention, which was statistically non significant improvement. Knowledge regarding Period of completion of immunization had increased significant. $(\mathrm{P}$ value $=0.001)$. Knowledge level regarding adverse effect of not immunizing children was increased from $22 \%$ to $31 \%$ with intervention ( $\mathrm{P}$ value $>0.05$ ).

Table: 3 Knowledge of the respondents regarding immunization

\begin{tabular}{|c|c|c|c|}
\hline $\begin{array}{c}\text { Have you heard about } \\
\text { Immunization }\end{array}$ & $\begin{array}{c}\text { Pre Testing } \\
\text { Frequency }(\%)\end{array}$ & $\begin{array}{c}\text { Post Testing } \\
\text { Frequency }(\%)\end{array}$ & P value \\
\hline Yes & $31(86.1)$ & $33(91.7)$ & \multirow[t]{2}{*}{0.45} \\
\hline No & $5(13.9)$ & $3(8.3)$ & \\
\hline \multicolumn{4}{|l|}{ Importance of Immunization } \\
\hline Yes & $7(19.4)$ & $10(27.8)$ & \multirow[b]{2}{*}{0.54} \\
\hline No & $29(80.6)$ & $26(72.2)$ & \\
\hline \multicolumn{4}{|l|}{$\begin{array}{l}\text { Period of completion of } \\
\text { immunization was }\end{array}$} \\
\hline Correctly Known & $28(77.8)$ & $33(91.6)$ & \multirow{2}{*}{0.00} \\
\hline Unaware about the period & $8(22.2)$ & $3(8.3)$ & \\
\hline \multicolumn{4}{|l|}{$\begin{array}{l}\text { Adverse effect of not } \\
\text { Immunizing children }\end{array}$} \\
\hline Yes & $8(22.2)$ & $11(30.6)$ & \multirow[t]{2}{*}{0.54} \\
\hline No & $28(77.8)$ & $25(69.4)$ & \\
\hline
\end{tabular}

\section{Discussion}

The intervention study was conducted on disadvantaged community of Katahari VDC of Morang district. Hygiene promotion is all about changing behaviors. It refers to a planned approach to preventing diarrhoeal diseases through the widespread adoption of safe hygiene practices. Simply hand washing can prevent different diseases to $42 \%$ at community level. ${ }^{2}$

The knowledge regarding hand washing was high in study population even before the intervention. Eighty one percent of the respondents had complete knowledge regarding hand washing during pre-test which increased to $94 \%$ after intervention program. Similar observations were made by other researchers.

The study done by SK Ray et al in urban slum areas of West Bengal reported high knowledge regarding hand washing. ${ }^{9}$ In another study done in Coastal South India, by Datta $\mathrm{S}$ reported $83.41 \%$ of the mothers had knowledge about importance of hand washing in prevention of communicable diseases. ${ }^{10}$

Prior to intervention $86 \%$ of the respondents had heard and understood about the immunization which increased to $92 \%$ after 
intervening. The study done in India by Singh MC et al, reported that mothers had a fair knowledge regarding need for immunization but a poor knowledge regarding the diseases prevented and doses of the vaccines, ${ }^{11}$ also in the study done by Ahulbalia $^{12}$ in semi-urban area of Nepal. Similar observations are made in present study. However only $19 \%$ of the subjects were correctly knowing the importance of immunization before the intervention which improved to $28 \%$ after the intervention, which was statistically non significant improvement ( $\mathrm{P}$ value $>0.05)$. This low level of knowledge can be attributed to low level of literacy (not literate $75 \%$ ).

In the present study $64 \%$ of the respondents were female of which $87 \%$ were not literate. Similar results are observed in the study done by Donald reports that mothers who had received less formal education may be at greater risk of not being immunized. ${ }^{13}$

Knowledge regarding Period of completion of immunization had increased from $77.8 \%$ to $91.6 \%$ which was highly significant $(\mathrm{P}$ value $=0.00$ ).

However, answering to the question prior to the intervention regarding adverse effect of not immunizing children $22 \%$ said that the child will develop deformity, which increased to $31 \%$ after intervention. Similar findings were also shown by $\mathrm{N}$ Jha et al. ${ }^{14}$ This emphasize that needy areas under immunization programme should be focused during intervention.

\section{References}

1. Hardy Jay, Hand washing facts, Hardy Diagnostics, www. hardydiagnostics.com/articles/ hand-washing.pdf assessed on 10 Aug 2012.

2. Curtis $\mathbf{V}$, Effect of washing hands with soap on diarrhea risk in the community: a systematic review, Lancet Infect Dis. 2003 May;3(5):27581.
Thus in the present study hand washing demonstration has produced positive changes while immunization knowledge level needs more attention.

Hence, we would recommend; continue to use demonstration technique to improve hand washing knowledge \& practice and wide approach intensive awareness program supported by community leaders, teachers, all level of health personnel, I/NGOs and Government of Nepal to enhance knowledge about immunization.

\section{Acknowledgement}

The author would like to thank the Management board of Nobel Medical College Teaching Hospital and Research Center for the financial support for the study. Special thanks go to the Kathari VDC people who had participated in the program, also all MBBS students of 2009 batch who helped in the collection of data.

\section{Limitation of the study}

The impact of the program was not assessed due to time constraints, which is essential since studies report that single intervention not supported by follow-up may have limited results and not lead to sustainable health improvement. ${ }^{15}$

3. Luby $\mathbf{S}$ et al. Effect of hand washing on child health: a randomized controlled trial, 2005.

4. Global Hand Washing Day, planners guide, Second edition.

5. Will Tillett, Appropriate approaches to hygiene and environmental sanitation in remote communities of Mugu and Humla Districts, Western Nepal. Technical Department, WASH sector, ACF-France, 2008. 
6. Well fact sheet, www.iboro. uk/well/ resources/facts-sheets/Handwashing, assessed on 6th Aug 2012.

7. Unicef, water sanitation and hygiene annual report, 2005.

8. Annual Report, Government of Nepal, Department of Health services, Kathmandu, Nepal 2067/68

9. Ray SK, Dobe M, Maji S, Chakrabarty D, Sinha Roy AK, Basu SS., A pilot survey on hand washing among some communities of West Bengal, Indian Journal of Public Health, OctDec, 2006, Volume 50, 225-230.

10. Datta $\mathbf{S}$, Knowledge and practice of hand washing among mothers of fewer than five children in rural coastal South India, International Journal of Medicine and Public Health, Jan-Mar, 2011, Volume 1, 33-38.
11. Singh MC, Badole CM, Immunization coverage and the knowledge and practice of mothers regarding immunization in rural area, Indian Public Health Association, Calcutta, INDE1957.

12. Ahulbalia, Immunization coverage of children in a semi-urban village panchayat in Nepal, 1985.

13. Donald Matsuda, Beliefs About Immunization and Children's Health Among Childbearing Mothers in Nepal, Thesis work, 2002.

14. Jha N, Kumar S, Yadav BK, Singh GC, Niraula SR, Impact of family health exercise program on health knowledge and practice of a rural population of eastern Nepal. Kathmandu University Medical Journal, Jan-Mar, 2006 Volume 4.

15. S Kathleen, Well factsheet, Sustaining Hygiene Behaviours, www.lboro.ac.uk/well assess on 6th Aug 2012.

Address of Correspondence: Mr.Ra eev Karn, Lecturer, Nobel Medical College, Kanchanbari, Biratnagar 